\title{
New CMA president urges catalytic action
}

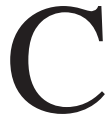

all it the next populist wave from the west: "Triple-E health care."

It stands for "efficiency, effectiveness and effecting change," the new president of the Canadian Medical Association, Dr. Anne Doig, said in her inaugural address at the CMA's 142nd annual general meeting in Saskatoon, Saskatchewan.

Arguing that "Canadians are not getting the bang for the considerable bucks that we are spending," Doig said efficiency is more than just a function of dollars; it's a direct reflection of the mechanisms used for delivering health care. "The issue is not how to do more with less. The issue is how to do better."

Effectiveness in the context of medical care, she added, means "ensuring the system is meeting the needs of patients."

"As physicians, we can each make small improvements that incrementally translate into systemic improvements in quality care. It is not enough to point the finger at others to improve — because as well all know — when you point the finger at someone else, there are three fingers pointing back at you. We have evidence on what we can do to provide more effective care and we have a professional commitment to put that into practice. That strikes at the heart of who we are as physicians, as professionals. We don't wait for someone else to fix a problem; we get to work and fix it ourselves."

As for "effecting change," Doig cast the concept in terms of the willingness of the medical profession to "lead."

"The past century, and particularly, the past 50 years, has seen an exponential increase in the volume of medical knowledge and in the technologies available to assist physicians to apply that knowledge. It has seen changes in the models of medical collegial care, as well as in the models of collaborative interdisciplinary care. Physicians have

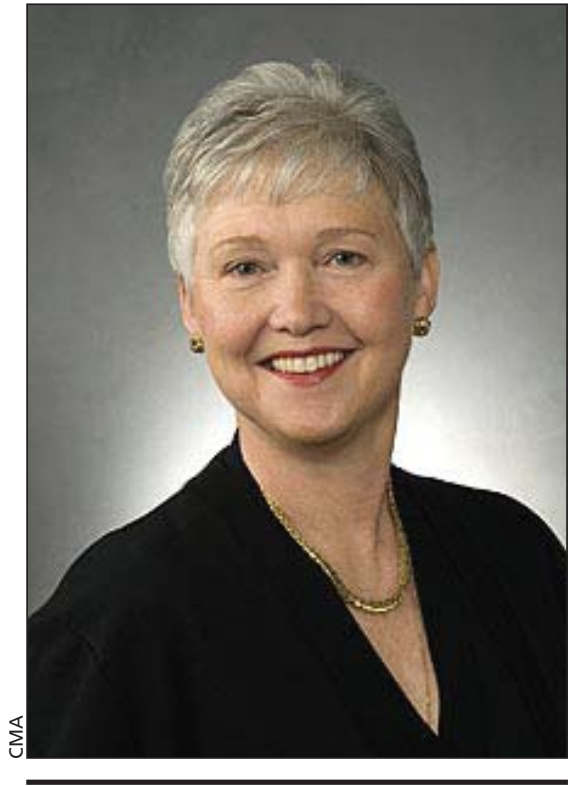

New CMA president Dr. Anne Doig says that "Canadians are not getting the bang for the considerable bucks that we are spending."

always embraced and indeed have led change that was for the benefit of their patients."

"We will continue to do so," she said.

Doig, though, remained steadfast in her refusal to articulate her personal views on medicare.

"In the past few weeks, I have been asked many times whether I support medicare," she said. "Implicit in this question is an underlying false assumption - that the desire to improve the system of health care delivery means choosing something other than medicare. That is a scare tactic, and one to which I refuse to succumb."

She later recounted the actions of her father and other Saskatchewan physicians as they stood against the provincial government's introduction of medicare in 1962 and their eventual decision to withdraw their services.

The holdout ended with the signing of Saskatoon Agreement, the crux of which, Doig said, "was the concession by the government that it would not interpose itself between the patient and the physician in decisions about necessary care."

"It's a quirk of history that physicians have largely been cast as villains in accounts of this critical time in Canada's history. If standing up to put the needs of patients first is being a villain, then I'm ready to be fitted for my black hat."

Doig cast CMA's transformation agenda as being similarly patientcentred. "Going forward, we must be clear that the issue is care, not medicare."

Asked later by reporters if her comments, and the agenda itself, are a signal that the nation's physicians are in the mood to launch an all-out assault on medicare, Doig responded that "some of the previous meetings of general council have been distracted by peripheral issues that took away from the debate. This debate was very focused."

"The tenets of medicare are very simple. No one should go without needed medical care because of an inability to pay for care. That's one. The second is that physicians support public funding of medicare. That's two. So the care agenda is: we need to work on the areas of effectiveness because that's part of how we fix the system."

"We will have more credibility and we will have more authority behind our demands to government to, if you will, fix their side of the equation, if we have done our work and our homework to address the things that we can address. There are systemic inefficiencies for which, quite frankly, physicians need to be accountable. There are also systemic inefficiencies that governments, health authorities, regions, hospitals, have to take responsibility and accountability for," Doig added. - Wayne Kondro, CMAJ

DOI:10.1503/cmaj.109-3025 